Удк 332.1

\title{
КАЧЕСТВО ГОРОДСКОЙ СРЕДЫ: ВОПРОСЫ ОРГАНИЗАЦИИ И СОЦИАЛИЗАЦИИ ОБЩЕСТВЕННОГО ПРОСТРАНСТВА
}

\author{
Артемова Ольга Васильевна, \\ artemova.ov@uiec.ru \\ Савченко Анастасия Николаевна, \\ savchenko.an@uiec.ru \\ Челябинский филиал Института экономики УрО РАН, \\ Россия, 454091, г. Челябинск, ул. Коммуны, 68.
}

\begin{abstract}
Артемова Ольга Васильевна, доктор экономических наук, директор Челябинского филиала Института экономики УрО РАН.
\end{abstract}

Савченко Анастасия Николаевна, кандидат экономических наук, старший научный сотрудник Челябинского филиала Института экономики УрО РАН.

Рассматриваются подходы к определению понятия «общественное пространство города». Представлена классификация видов общественных пространств, в том числе по новым признакам, введенным авторами (жизненный цикл человека, природно-климатические условия территории). Определено влияние общественного пространства города на социализацию местного сообщества; показано, что его содержательная наполняемость связана с вовлеченностью и активностью граждан. Выявлены проблемы в организации общественного пространства, предложен алгоритм действий по участию граждан в его преобразовании. Обоснована целесообразность использования проектного подхода к управлению городскими общественными пространствами. Цель исследования - рассмотреть, как общественное городское пространство, его состояние и особенности влияют на социализацию городского сообщества. Методы: пространственный подход к анализу городской среды, группировка и классификация видов общественных пространств, кейс-анализ практик организации общественных пространств. Результаты: уточнены место и роль общественных пространств города в развитии городской среды, определены признаки их социализации, предложена матрица на основе признаков классификации общественных территорий как инструмент организации общественных городских пространств для различных групп населения.

Ключевые слова: Общественные блага, городская среда, организация общественного пространства, социализация общественного пространства.

\section{Введение}

Важнейшие приоритеты в развитии страны, регионов, отдельных территорий обозначены в Указе Президента о национальных целях развития России до 2030 года [1]. В частности, речь идет о сохранении населения, здоровья и благополучии людей, о комфортной и безопасной среде для жизни. Развитие территории (от небольшого населенного пункта до мегаполиса) в соответствии с этими приоритетами приводит к повышению качества жизни населения. Исследователи едины в том, что качество жизни населения (КЖН) - сложное синтетическое понятие, оно охватывает уровень жизни, но не сводится к нему. В основе КЖН - потребности материального характера и более высокого уровня, необходимые для всестороннего развития личности. Это и образ жизни, стиль жизни, условия (среда) проживания людей [2]. Каждый компонент, характеризующий КЖН, важен с позиций достижения благополучия и безопасности людей. 
В этом контексте интерес представляет анализ условий проживания людей в городах, качества городской среды и, в частности, состояния и развития общественных городских пространств.

Почему возникает вопрос о необходимости осмысления вопроса об общественных пространствах города в контексте исследований КЖН? Отметим несколько причин:

1. Общественному пространству (ОП) до недавнего времени не придавалось серьезного значения.

2. Толкованию понятия общественного пространства, классификации его видов, функций, оценке состояния и качества не уделялось должного внимания, что не позволяло предметно и конструктивно обсуждать вопросы обустройства и организации общественных пространств.

3. Отсутствовал комплексный подход в вопросах обустройства и управления общественным городским пространством.

4. Не в полной мере учитывались такие особенности общественного пространства, как жизненный цикл человека (ЖЦЧ), природно-климатические условия проживания людей на конкретной территории.

Действительно, в настоящее время есть вопросы к качеству городского общественного пространства. К сожалению, исторически так сложилось, что зачастую игнорировались индивидуальные особенности и потребности населения конкретных советских городов, их исторического развития и окружающего ландшафта [3]. Оно формировалось зачастую стихийным, случайным образом; ткань общественного пространства имела и до сих пор сохраняет фрагментарный характер, в нем присутствуют признаки не связанности. При проектировании и строительстве жилья (особенно массовой застройки) специалисты часто не придают должного значения вопросам окружающей среды, достаточности инфраструктуры. Есть проблемы доступности общественного пространства (по вместимости, расположению, безопасности для населения и отдельных социальных групп). Слабо выражены социальные функции общественного пространства, низка его наполняемость и активность пользователей.

В этой связи следует согласиться с мнением о том, что общественные пространства характеризуются неудовлетворительным моральным и физическим состоянием и несоответствием их функционального наполнения, снижающими социальную эффективность пространств города [4].

Авторам представлялось целесообразным в широком спектре исследований, посвященных изучению качества жизни населения, выделить конкретный аспект, которому в меньшей степени уделялось внимание, но который важен с позиций формирования социального пространства города и активных коммуникаций его жителей. Именно это и определило цель исследования - выявить, как общественное городское пространство, его состояние и особенности влияют на социализацию городского сообщества.

Авторы разделяют подход исследователей, которые определяют общественное пространство как пространство общения и социальной активности, организованное в соответствии с доминирующей функцией [5]. Однако вопрос о доминирующей функции решается по-разному в зависимости от классификации и структурирования общественных пространств, наличия тех или иных социальных групп городского сообщества. В данном исследовании в качестве рабочего варианта используется понятие общественного пространства как городской территории, предназначенной для общественного пользования, сложившейся исторически, учитывающей экономические, социальные, культурные и другие признаки.

Подчеркнем, что общественные пространства обладают такими свойствами общественного блага как несоперничество и неисключаемость. Несоперничество подразуме- 
вает то, что потребление одного индивида не уменьшает возможности потребления (присутствия) другого индивида. Неисключаемость выражается в невозможности или запретительно высоких издержках доступа к благу дополнительных потребителей. Блага, которым оба свойства присущи в высокой степени, называются чистыми общественными благами.

Общественные блага являются предметом исследований многих авторов, в частности выделяют общенациональные и локальные общественные блага, различия между которыми определяются разницей в территориальном охвате полезным действием того или иного блага [6]. Свойства общественного блага необходимо иметь в виду при исследовании общественного пространства. При этом значение имеют масштабы его территориального охвата.

Общественные городские пространства многообразны. Их исследование приводит к необходимости классификации видов общественных пространств и их систематизации. Так, с учетом пространственного фактора общественные пространства города разделяются на открытые, являющиеся частью городского ландшафта, и закрытые, расположенные на изолированных территориях (в том числе, имеющие точечный характер и не оказывающие влияния на изменение городской среды в целом). К открытым относятся урбанистические пространства, предназначенные преимущественно для публичного использования (площади, пешеходные дорожки, улицы); «зеленые» зоны и места отдыха (парки, скверы, бульвары), которые в последнее время активно используются как публичные пространства [7].

Применяется и такой классификационный признак общественных пространств, который связан с локацией территории на «центр-периферия». Центральные (общегородские) пространства - это площади, парки, пешеходные зоны, набережные. Периферийные пространства (районного значения) относятся к территориям перед кинотеатрами, скверы, зеленые зоны [7].

По функционалу выделяют пять типов общественных пространств, необходимых современному городу: социально-событийные (например, площади); культурнодосуговые (театры, кинотеатры и открытые пространства рядом с ними; зеленые рекреации (парки и скверы); политические (такие, как Гайд-парк); обыденные - дворы, придомовые детские и спортивные площадки [8].

Представляется, что важными классификационными признаками при анализе видов общественных пространств являются: жизненный цикл человека и природноклиматический фактор. Учет жизненного цикла человека означает удовлетворение потребностей человека по использованию общественного пространства в любом возрасте - от младенчества до преклонных лет. Необходимо исходить из того, что имеются разные группы пользователей территории с разными интересами и возможностями, которые должны комфортно сосуществовать друг с другом.

Природно-климатический аспект оказывает огромное влияние на формирование общественных пространств города (речь идет о температурном, влажностном, ветровом режимах, а также количестве осадков). При этом важно учитывать, что для многих российских городов, находящихся в зоне сурового климата, продолжительный зимний период с низкими отрицательными температурами вносит существенные коррективы в организацию и использование общественных пространств гражданами. Однако нельзя допускать сезонных выпадений при использовании общественных пространств.

Специалисты отмечают, что многие проекты благоустройства трактуются в основном в формате летнего времени, а проработанность проектов общественных пространств с позиции круглогодичного использования достаточно слабая. В то же время 
мировая и отечественная практика показывает, что суровые природные условия не всегда являются помехой для создания привлекательного общественного пространства [9]. Так, зарубежные специалисты отмечают, что развитие города в зимний период с точки зрения формирования позитивного восприятия городских пространств возможно при создании продуманного дизайна, инфраструктуры, а также при проведении ярких событий и фестивалей [10]. За рубежом разрабатываются инновационные проекты, основанные на концепции максимального использования потенциала городского пространства и его популяризации в условиях сурового климата [11].

\section{Наполнение и социализация общественного пространства города}

Общественное пространство города - не абстракция, не обезличенное понятие, не имеющее связи с реальностью, оно имеет содержательную субстанцию. Это касается объектной составляющей, но главное - в нем присутствует субъектная основа, т. к. речь идет о субъектах, которые проживают, ведут деятельность, взаимодействуют в конкретном месте и в конкретное время. Такой подход вписывается в более широкий контекст исследований. Так, в отношении экономического пространства есть понимание его как формы не только объектного, но и субъектного бытия экономики. Это означает, что экономическое пространство обладает собственным субъектным потенциалом, реализует и воспроизводит его, распределяя как вещественные ресурсы, так и ресурсы субъектного характера [12]. Считаем, что такой подход оправдан и в отношении общественного городского пространства. Отчуждение человека от места его проживания, формальное присутствие его в общественном городском пространстве имеет негативные последствия: апатию, отсутствие активности и мотивации к творческой деятельности, обезличивание и формализацию коммуникаций. Отсюда актуализируются вопросы вовлеченности, проактивной деятельности человека, социальных групп в решение вопросов городской жизни, организации того общественного пространства, в котором они присутствуют.

Анализируя вопросы социализации общественного пространства, исходим из того, что, с одной стороны, оно обладает определенной локализацией в физическом пространстве, речь идет о понимании «места» [12]; с другой - в нем присутствует социальный агент, который занимает определенное положение в пространстве социальном [13]. Важно понимать, что общественное пространство постигается не только через объектно-вещественную составляющую, но и через взаимосвязи между индивидами, группами людей, имеющими свой социальный статус.

В практическом плане это означает, что городские власти должны сконцентрировать усилия на таких стратегических направлениях, как развитие инфраструктуры, т. е. базовых условий для комфортной жизни, работы, отдыха и создание позитивного психологического климата в городе путем формирования интересного, безопасного, подвижного, энергичного, доброжелательного городского сообщества [14].

Городское общественное пространство имеет наполнение [15], которое выражается в архитектурном ландшафте; дизайне как художественном проектировании процессов жизнедеятельности; визуальной коммуникации, активности субъектов посредством культурных, спортивных, досуговых, политических и иных мероприятий для отдельных групп граждан и населения в целом; вовлеченности граждан в обустройство территории их проживания. В противном случае если оно пустое, нельзя говорить о городском сообществе, а значит, перед нами поселение, агломерация, слобода, но не город [16].

Поведение жителей формируется в определенной городской среде, при этом очевидно их взаимное влияние. Специалисты отмечают, что городская среда влияет на со- 
циальную жизнь и личные отношения [17], при этом при наличии финансовых средств и технологий трансформировать городскую среду можно достаточно быстро, а вот повысить общий уровень культуры, образования, добрососедства и изменить целевые установки жителей намного труднее [14]. Важно понимать, что легко разрушить коммуникации между людьми, доверие и социальные связи, остановить диалог в городе. В связи с этим актуализируется вопрос о социализации общественного пространства. При этом важна грамотная работа специалистов по обустройству общественных мест, которая способствует развитию городской общественной жизни, улучшению ее качества, повышению безопасности и комфортности городской среды [18].

Здесь уместно упомянуть о проекте «Поддержка институтов гражданского общества в вовлечении населения в благоустройство дворовых территорий и развитие комфортной городской среды», реализуемом при поддержке Института экономики города [19].

Деятельность в рамках проекта направлена на оказание содействия институтам гражданского общества на всей территории Российской Федерации, а разрабатываемые рекомендации тестируются в пилотных территориях проекта - пяти городах, расположенных в разных субъектах Российской Федерации. Отмечая низкий уровень общественного участия в формировании городской среды, неудовлетворенность деятельностью муниципалитетов, слабую обратную связь с населением, специалисты ИЭГ считают, что городским сообществам необходимо использовать концептуально новые подходы к формированию городской среды и технологиям консолидации интересов, усилий и финансовых ресурсов всех заинтересованных участников.

\section{Проблемы управления общественным пространством города}

Общественное пространство - сложный объект для управления, сопряженный со многими проблемами $[16,20,21]$. Отметим среди них важнейшие:

- неэффективное использование общественных территорий, связанное, в частности, с несогласованностью интересов и действий представителей власти и местного самоуправления, частных компаний, населения;

- неэффективное использование бюджетных средств на эксплуатацию и содержание объектов, находящихся на территории общественных пространств;

- неисполнение управленческих решений и недостижение целей по организации общественных пространств;

- недостаток квалифицированных управленческих кадров;

- слабые вовлеченность и организованность граждан по преобразованию среды своего проживания.

Названные проблемы связаны с решением вопросов о согласовании действий инициаторов и участников, заинтересованных в обустройстве общественных пространств (рис. 1).

Учитывая разнообразные потребности, интересы, мотивацию участников преобразования общественных пространств города, следует констатировать, что это пространство приобретает фактор сценарности [4]. Реализовать его возможно, учитывая, что ОП города динамично, оно постоянно трансформируется, адаптируется для новых функций, чтобы соответствовать изменяющимся потребностям людей. Проектировщики имеют возможность моделировать то, каким должно быть пространство, удовлетворяющее всему комплексу физических, психологических, эстетических и других потребностей человека. При этом возможны разные варианты и способы управления общественным пространством: программное, проектное управление, управление по результатам и т. п. При выборе вариантов и способов управления общественным про- 
странством необходимо взвесить все «за» и «против» [22]. Авторы полагают, что целесообразно использовать проектный подход к организации ОП, который обоснован следующими обстоятельствами:

- большая степень неопределенности и несогласованность интересов по вопросам организации общественного пространства;

- постановка конкретной количественно измеримой цели и достижение запланированных результатов в установленные сроки;

- ограниченность во времени и ресурсах, необходимость их эффективного использования;

- необходимость межведомственного взаимодействия в процессе благоустройства общественных территории;

- наличие новизны и уникальности проектов по обустройству общественного пространства.

Выявление потребностей и запросов различных социальных групп граждан на совместную организацию и использование общественных пространств Identification of the needs and demands of various social groups of citizens for the joint organization and use of public spaces
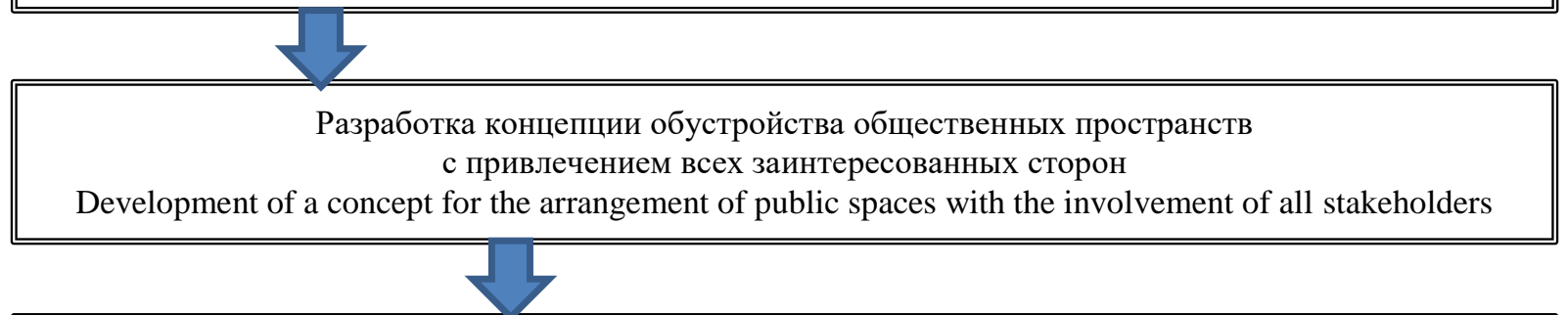

Консолидация интеллектуальных, организационных, трудовых, финансовых и иных ресурсов участников городских сообществ по организации общественных пространств

Consolidation of intellectual, organizational, labor, financial and other resources of participants in urban communities for the organization of public spaces

Разработка механизма участия местного сообщества, граждан в реализации концепции благоустройства общественных пространст

Development of a mechanism for participation of the local community, citizens in the implementation of the concept of the improvement of public spaces

Мониторинг и общественный самоконтроль за действиями по разработке

и реализации проекта благоустройства общественных пространств

Monitoring and public self-control over actions for the development and implementation of a public space improvement project

Определение порядка совместного использования общественных пространств Determination of the procedure for the joint use of public spaces

Puс. 1. Алгоритм действий участников преобразования общественных пространств города

Fig. 1. Algorithm of actions of participants in the transformation of public spaces of the city 
Именно с учетом этих обстоятельств сегодня реализуются важнейшие проекты по улучшению городской среды. Речь идет о национальных проектах, которые призваны решать проблемы, жизненно важные для страны, региона, конкретной территории, отдельного человека. На каждом уровне управления проектами (федеральном, региональном, муниципальном) решаются вопросы, входящие в компетенцию органов соответствующего уровня управления. Применительно к национальному проекту «Жилье и городская среда» уровневая структура его реализации представлена на рис. 2.

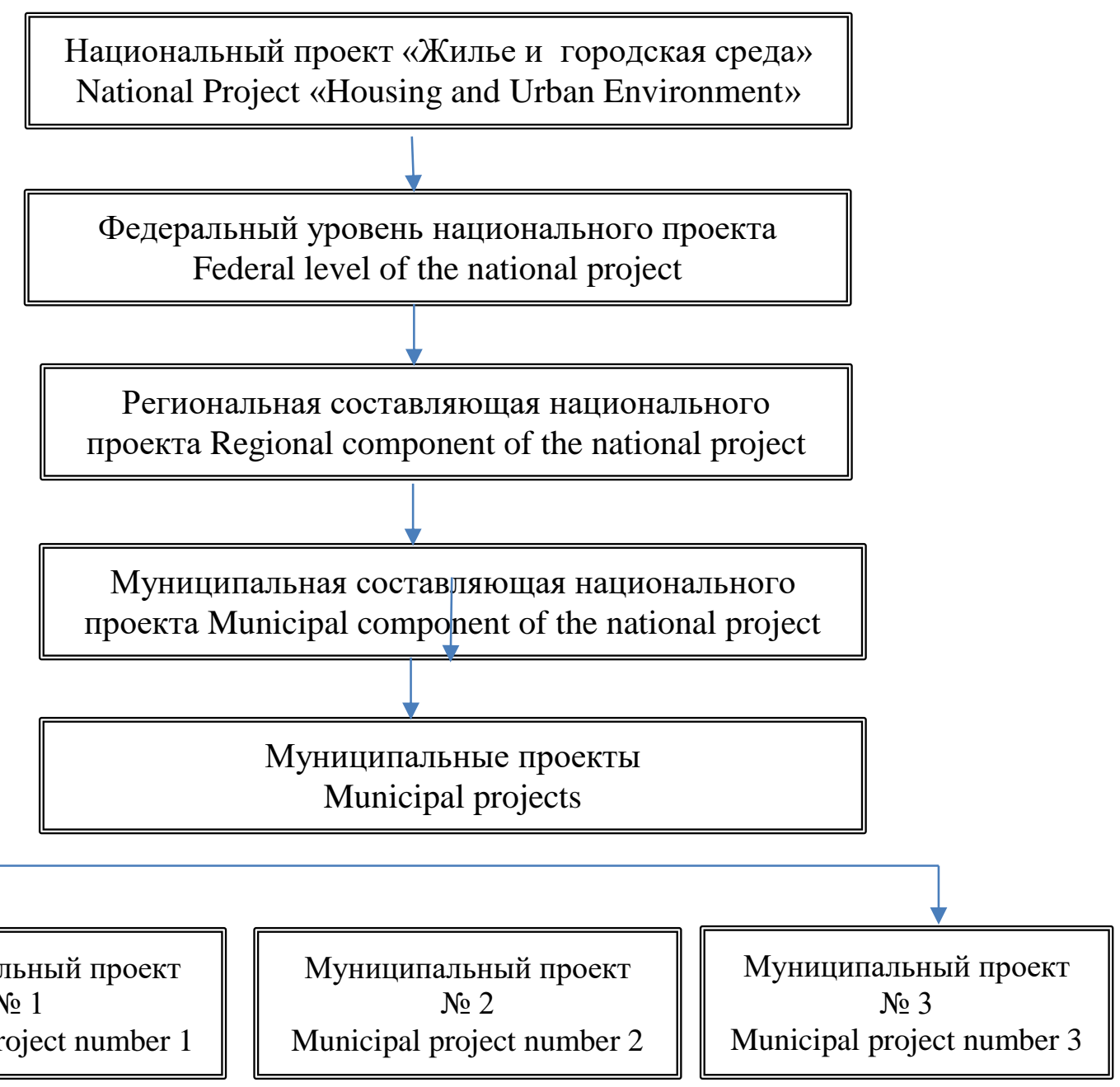

Puc. 2. Управление городской средой с использованием проектного подхода в рамках национального проекта «Жилье и городская среда»

Fig. 2. Management of the urban environment using a project-based approach within the framework of the national project «Housing and Urban Environment»

Национальный проект «Жилье и городская среда» включает федеральную, региональную и муниципальную составляющие. Муниципальная составляющая реализуется через муниципальные проекты, которых может быть несколько. Например, в г. Челябинске таких проектов три: 1) обеспечение устойчивого сокращения непригодного жилого фонда; 2) формирование комфортной городской среды; 3) жилье. В контексте данного исследования мы акцентировали внимание на формировании городской среды (проект № 2), а именно состоянии и развитии общественных пространств, по поводу которых в муниципальном проекте отмечена необходимость определения порядка отбора обществен- 
ных территорий, подлежащих благоустройству в первоочередном порядке. При этом обязательным моментом является рейтинговое голосование по отбору этих территорий.

Вовлечение граждан в преобразование территорий своей жизнедеятельности - необходимое условие социализации городского пространства. Например, в г. Тюмени приоритетность организации общественных пространств определяется на основе интернет-голосования с использованием модуля официального портала администрации города и системы электронных опросов «Я решаю!». По результатам составляется рейтинговая таблица, в которой место ОП в рейтинге зависит от числа голосов участников. Так, в первой десятке рейтинга присутствуют такие объекты, как парки, скверы, культурно-досуговые площадки. По востребованности чаще всего упоминается озеленение территорий с конкретной привязкой к месту.

В Томске при администрации города проходят активные обсуждения дизайнпроектов общественных пространств по благоустройству парков (в том числе, рекреационных), скверов, бульваров, детских площадок, пешеходных зон и др. В Томской области благоустройством общественных пространств занимается креативная команда Центра развития городской среды.

Кейс-анализ практик обустройства общественных пространств российских городов показал, что ориентир взят в направлении развития общественных пространств (это отражено в той или иной степени в стратегических документах городов), разрабатываются проекты их обустройства с привлечением всех заинтересованных сторон, в том числе широкой общественности. Однако это отражает лишь общую позитивную тенденцию в развитии общественных мест, в то время как в отдельных городах ситуация складывается по-разному.

Для понимания масштабов проблем и ситуации с обустройством общественных пространств уральских и сибирских городов (крупнейших и крупных) представим результаты ранее проведенных исследований, по оценке качества городской среды. Так, например, по методике формирования индекса качества городской среды, утвержденной Правительством РФ, были использованы индикаторы, характеризующие общую (интегральную) оценку городской среды (максимальное значение - 360 баллов) и шесть видов городской среды: жилье, уличная инфраструктура, озеленение территорий, общественно-деловая инфраструктура, социально-досуговая инфраструктура, общегородское пространство (каждый вид оценивался от 0 до 60 баллов). Полученная в результате комплексная оценка городской среды характеризовала уровень комфортности проживания на соответствующей территории. При этом благоприятной средой считалось состояние городской среды, при котором количество набранных баллов составляло более 50 \% максимально возможного количества баллов индекса города; неблагоприятной - количество набранных баллов составляло менее $50 \%$.

Индексы анализируемых городов представлены в табл. 1.

В группе крупнейших городов интегральная оценка качества городской среды в 2019 г. выше 50 \% (благоприятно) у Екатеринбурга и Красноярска, при этом незначительное повышение за год произошло только в двух городах: Челябинске и Омске. Оценка общественного пространства выше 50 \% (благоприятно) у трех городов: Екатеринбурга, Новосибирска, Красноярска; ее повышение имело место во всех городах этой группы, за исключением Екатеринбурга. Интересно отметить, что Екатеринбург, занимая 1-е место по интегральной оценке качества городской среды, имеет 2-е место по оценке общественного пространства.

Ситуация в группе крупных городов следующая. Города, имеющие в 2019 г. интегральную оценку выше 50 \% (благоприятно): Тюмень, Магнитогорск, Иркутск, Кемерово; повысили за год интегральную оценку четыре города: Тюмень, Кемерово, Ир- 
кутск и Томск. Оценка общественного пространства в 2019 г. выше 50 \% (благоприятно) у всех городов, за исключением Кургана. При этом Тюмень заняла 1-е место по интегральной оценке качества городской среды и 5-е место по оценке общественного пространства, в то время как Барнаул имел 4-е место по интегральной оценке и 1-е по оценке общественного пространства. В целом просматривается позитивная тенденция в развитии общественных пространств анализируемых городов (крупнейших и крупных), причем более высокие оценки общественных пространств, чем интегральные, свидетельствуют об активности преобразований этих общественных территорий.

Таблица 1. Индексы качества городской среды, 2019 [23]

Table 1. Urban environment quality indices, 2019 [23]

\begin{tabular}{|c|c|c|c|c|c|c|c|c|}
\hline \multirow{3}{*}{$\begin{array}{l}\text { Город } \\
\text { City }\end{array}$} & \multicolumn{4}{|c|}{$\begin{array}{c}\text { Интегральная оценка } \\
\text { Integral assessment }\end{array}$} & \multicolumn{4}{|c|}{$\begin{array}{c}\text { Оценка общегородского пространства } \\
\text { Citywide assessment }\end{array}$} \\
\hline & \multicolumn{2}{|c|}{2018} & \multicolumn{2}{|c|}{2019} & \multicolumn{2}{|c|}{2018} & \multicolumn{2}{|c|}{2019} \\
\hline & $\begin{array}{l}\text { Баллы } \\
\text { Points }\end{array}$ & $\begin{array}{l}\text { Рaнг } \\
\text { Rank }\end{array}$ & $\begin{array}{l}\text { Баллы } \\
\text { Points }\end{array}$ & $\begin{array}{l}\text { Ранг } \\
\text { Rank }\end{array}$ & $\begin{array}{l}\text { Баллы } \\
\text { Points } \\
\end{array}$ & $\begin{array}{l}\text { Ранг } \\
\text { Rank }\end{array}$ & $\begin{array}{l}\text { Баллы } \\
\text { Points }\end{array}$ & $\begin{array}{l}\text { Ранг } \\
\text { Rank } \\
\end{array}$ \\
\hline \multicolumn{9}{|c|}{$\begin{array}{l}\text { Крупнейшие города с численностью от } 1 \text { млн чел. } \\
\text { Largest cities with a population of } 1 \text { million or more }\end{array}$} \\
\hline $\begin{array}{c}\text { Екатеринбург (УрФО) } \\
\text { Yekaterinburg }\end{array}$ & 191 & 1 & 188 & 1 & 42 & 1 & 34 & 2 \\
\hline $\begin{array}{c}\text { Челябинск (УрФО) } \\
\text { Chelyabinsk } \\
\end{array}$ & 160 & 4 & 161 & 3 & 23 & 4 & 28 & 3 \\
\hline $\begin{array}{l}\text { Новосибирск (СФО) } \\
\text { Novosibirsk }\end{array}$ & 161 & 3 & 158 & 4 & 35 & 2 & 39 & 1 \\
\hline $\begin{array}{l}\text { Красноярск (СФО) } \\
\text { Krasnoyarsk } \\
\end{array}$ & 189 & 2 & 181 & 2 & 33 & 3 & 39 & 1 \\
\hline $\begin{array}{c}\text { Омск }(\mathrm{C} Ф О) \\
\text { Omsk }\end{array}$ & 104 & 5 & 106 & 5 & 23 & 4 & 26 & 4 \\
\hline \multicolumn{9}{|c|}{$\begin{array}{l}\text { Крупные города с численностью от } 250 \text { тыс. человек до } 1 \text { млн чел. } \\
\text { Large cities with a population of } 250 \text { thousand to } 1 \text { million people }\end{array}$} \\
\hline $\begin{array}{l}\text { Тюмень (УрФО) } \\
\text { Tyumen }\end{array}$ & 212 & 1 & 219 & 1 & 28 & 7 & 31 & 5 \\
\hline $\begin{array}{l}\text { Курган (УрФО) } \\
\text { Kurgan }\end{array}$ & 165 & 7 & 161 & 7 & 26 & 8 & 28 & 7 \\
\hline $\begin{array}{c}\text { Магнитогорск (УрФО) } \\
\text { Magnitogorsk } \\
\end{array}$ & 189 & 2 & 184 & 2 & 31 & 4 & 30 & 6 \\
\hline $\begin{array}{c}\text { Нижний Тагил }(У p Ф О) \\
\text { Nizhny Tagil }\end{array}$ & 167 & 6 & 163 & 6 & 40 & 1 & 30 & 6 \\
\hline $\begin{array}{c}\text { Иркутск (СФО) } \\
\text { Irkutsk } \\
\end{array}$ & 180 & 3 & 181 & 3 & 30 & 5 & 32 & 4 \\
\hline $\begin{array}{c}\text { Кемерово (СФО) } \\
\text { Kemerovo } \\
\end{array}$ & 179 & 4 & 181 & 3 & 33 & 3 & 35 & 3 \\
\hline $\begin{array}{c}\text { Барнаул (СФО) } \\
\text { Barnaul } \\
\end{array}$ & 179 & 4 & 179 & 4 & 29 & 6 & 38 & 1 \\
\hline $\begin{array}{l}\text { Томск }(\mathrm{C} Ф О) \\
\text { Tomsk }\end{array}$ & 170 & 5 & 176 & 5 & 35 & 2 & 36 & 2 \\
\hline
\end{tabular}

Для расширения и активизации деятельности по обустройству общественных городских пространств предложено исходить из необходимости охвата всех групп населения как пользователей ОП. Кроме того, нужно учитывать природно-климатический фактор той или иной территории, не допускать выпадающих сезонов в использовании общественных мест в городах с суровым климатом. В связи с этим в порядке конкретизации приводим матрицу организации общественных пространств города с учетом та- 
ких составляющих (признаков), как жизненный цикл человека и климатические условия территории проживания (табл. 2).

\section{Таблища 2. Организация общественных городских пространств для жителей города} Table 2. Organization of public urban spaces for city residents

\begin{tabular}{|c|c|c|c|}
\hline \multicolumn{2}{|c|}{$\begin{array}{l}\text { Признаки класси- } \\
\text { фикации обще- } \\
\text { ственных про- } \\
\text { странств } \\
\text { Signs of the classifi- } \\
\text { cation of public } \\
\text { spaces }\end{array}$} & $\begin{array}{l}\text { Локализация общественных пространств } \\
\text { (открытые-закрытые пространства, } \\
\text { центр-периферия) } \\
\text { Localization of public spaces (open-closed } \\
\text { spaces, center-periphery) }\end{array}$ & $\begin{array}{c}\text { Доминирующая функция общественных } \\
\text { пространств } \\
\text { Dominant function of public spaces }\end{array}$ \\
\hline \multirow{4}{*}{ 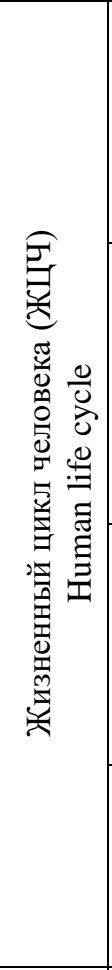 } & 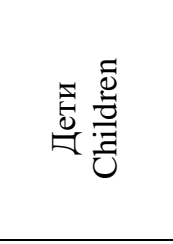 & $\begin{array}{c}\text { В основном закрытые пространства на } \\
\text { периферии (дворы, территории возле дет- } \\
\text { ских учреждений) } \\
\text { Mostly closed spaces in the periphery (court- } \\
\text { yards, areas near childcare facilities) }\end{array}$ & $\begin{array}{c}\text { Организация активного отдыха и прогу- } \\
\text { лок: детские (в т. ч. спортивные) пло- } \\
\text { щадки, пешеходные и вело зоны, парки } \\
\text { Organization of outdoor activities and } \\
\text { walks: children's (including sports) play- } \\
\text { grounds, pedestrian and bicycle zones, parks }\end{array}$ \\
\hline & 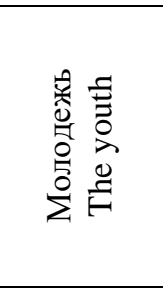 & $\begin{array}{c}\text { В основном открытые пространства в цен- } \\
\text { тральной части города } \\
\text { Mostly open spaces in the city center }\end{array}$ & $\begin{array}{c}\text { Организация культурных, спортивных, } \\
\text { развлекательных мероприятий, активного } \\
\text { отдыха: кафе, театры, клубы, фестивали, } \\
\text { стадионы } \\
\text { Organization of cultural, sports, entertain- } \\
\text { ment events, outdoor activities: cafes, thea- } \\
\text { ters, clubs, festivals, stadiums }\end{array}$ \\
\hline & 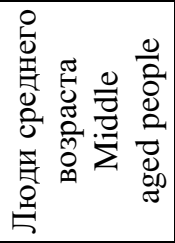 & $\begin{array}{c}\text { Открытые (центр, территория возле места } \\
\text { работы) и закрытые пространства (дворы, } \\
\text { микрорайон проживания) } \\
\text { Open (center, area near the place of work) and } \\
\text { closed spaces (courtyards, residential area) }\end{array}$ & $\begin{array}{c}\text { Организация культурных мероприятий, } \\
\text { отдыха: кафе, рестораны, театры, музеи, } \\
\text { парки, скверы } \\
\text { Organization of cultural events, recreation: } \\
\text { cafes, restaurants, theaters, museums, parks, } \\
\text { squares }\end{array}$ \\
\hline & 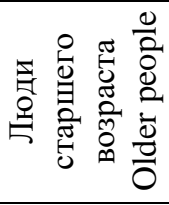 & $\begin{array}{l}\text { В основном закрытые пространства (дво- } \\
\text { ры, микрорайон проживания, территории } \\
\text { возле социальных объектов) } \\
\text { Mostly closed spaces (courtyards, residential } \\
\text { area, areas near social facilities) }\end{array}$ & $\begin{array}{c}\text { Организация отдыха и прогулок: парки, } \\
\text { скверы, пешеходные зоны Organization } \\
\text { of recreation and walks: parks, squares, } \\
\text { pedestrian zones }\end{array}$ \\
\hline \multirow{4}{*}{ 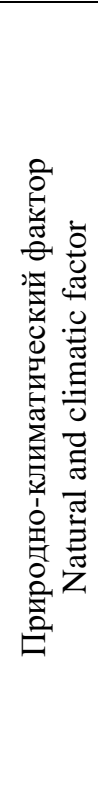 } & \multirow{4}{*}{ 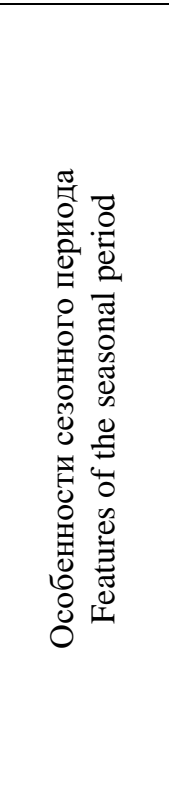 } & $\begin{array}{l}\text { Открытые пространства, на которые кли- } \\
\text { матические факторы не оказывают суще- } \\
\text { ственного влияния } \\
\text { Public spaces that are not significantly affect- } \\
\text { ed by climatic factors }\end{array}$ & $\begin{array}{c}\text { Организация деятельности в закрытых } \\
\text { помещениях (кафе, клубы, музеи и др.) } \\
\text { Organization of activities in closed spaces } \\
\text { (cafes, clubs, museums, etc.) }\end{array}$ \\
\hline & & $\begin{array}{c}\text { Открытые пространства, трансформируе- } \\
\text { мые в соответствии с сезоном } \\
\text { Public spaces, transformable according to the } \\
\text { season }\end{array}$ & $\begin{array}{c}\text { Сезонная адаптация общественных мест } \\
\text { и объектов (стадионы, пешеходные и } \\
\text { вело трассы) } \\
\text { Seasonal adaptation of public places and facili- } \\
\text { ties (stadiums, pedestrian and bike trails) } \\
\end{array}$ \\
\hline & & $\begin{array}{c}\text { Открытые пространства, предназначенные } \\
\text { для использования в летний период } \\
\text { Public spaces intended for summer use }\end{array}$ & $\begin{array}{c}\text { Организация мероприятий в открытых } \\
\text { пространствах } \\
\text { Organization of events in open spaces } \\
\end{array}$ \\
\hline & & $\begin{array}{l}\text { Открытые пространства, предназначенные } \\
\text { для использования в зимний период } \\
\text { Public spaces intended for winter use }\end{array}$ & $\begin{array}{c}\text { Использование объектов временной ар- } \\
\text { хитектуры как зимних сооружений с } \\
\text { особыми свойствами (снежные, ледовые } \\
\text { городки и др.) } \\
\text { Use of objects of temporary architecture as } \\
\text { winter structures with special properties } \\
\text { (snow, ice towns, etc.) }\end{array}$ \\
\hline
\end{tabular}


Использование предложенной матрицы как инструмента анализа востребованности общественных пространств города разными группами населения и в разные сезонные периоды (включая зимний) позволит учесть запросы жителей и оптимально обустроить общественные пространства на всей территории города.

\section{Заключение}

Подводя итоги, резюмируем основные положения и выводы. Во-первых, категория общественного пространства рассматривалась авторами в контексте субъектнообъектных отношений, что расширило и углубило понимание принципов функционирования городской среды и ее социализации. Во-вторых, уточнение и дополнение классификационных признаков общественных пространств позволило учесть запросы разных групп населения на использование городских территорий. В-третьих, была обоснована необходимость социализации общественного пространства города; вовлечения гражданского общества, различных социальных групп населения в преобразование общественных пространств, осуществления активных коммуникаций. В-четвертых, были выявлены проблемы управляемости общественными пространствами города. Обосновано, что для этого целесообразно использование проектного подхода в управлении. Кроме того, авторами приведены и прокомментированы результаты экспертной оценки городской среды в целом и общественных пространств для уральских и сибирских городов, отражающие ситуацию в обустройстве городских территорий. Результаты исследования могут быть использованы органами местного самоуправления для проектного управления общественными пространствами городов, реализации национальных проектов «Жилье и городская среда» на местном уровне.

Статья подготовлена в соответствии с Планом НИР ФГБУН «Институт экономики УрО РАН» на 20212.

\section{СПИСОК ЛИТЕРАТУРЫ}

1. Указ о национальных целях развития России до 2030 года. URL: http://kremlin.ru/acts/news/63728 (дата обращения 09.03.2021).

2. Управление качеством жизни населения: монография / С.Н. Яшин, Л.А. Мосина, С.Г. Захарова, Ю.С. Ширяева и др.; под общ. ред. С.Г. Захаровой. - Нижний Новгород: НИЦ «Открытое знание», 2019. - $157 \mathrm{c}$.

3. Агеев И.А. Методологический ресурс исторической урбанистики в современных исследованиях городских пространств // Вестник Томского государственного университета. - 2014. - № 385. - С. $79-84$.

4. Вотинов М.А. Особенности формирования общественных пространств в городской среде // Вестник БГТУ им. В.Г. Шухова. - 2014. - № 4. - С. 36-40.

5. Гельфонд А.Л. Общественное здание и общественное пространство. Дуализм отношений // Academia. Архитектура и строительство. - 2015. - № 2. - С. 20-33.

6. Якобсон Л.И. Государственный сектор экономики: экономическая теория и политика. - М.: ГУ ВШЭ, 2000. - $367 \mathrm{c.}$

7. Баталина Т.С. Анализ особенностей формирования общественного пространства // Бизнес и дизайн ревю. - 2017. - Т. 1. - № 1 (5). - С. 11.

8. Паченков О.В. Публичное пространство города перед лицом вызовов современности // Новое литературное обозрение. - 2012. - № 117 (5/2012). - С. 67-83.

9. Саляхова М.Р., Шульпина Ю.В. К вопросу об актуальности формирования временной архитектуры как способа преобразования общественных пространств в зимнее время // Известия КазГАСУ. 2019. - № 4 (50). - C. 120-130.

10. Xing C.B., Zhang J.F. The preference for larger cities in China: evidence from rural-urban migrants // China Economic Review. - 2017. - V. 43. - P. 72-90.

11. Fredhall ice falls // The official website Bureau UMA. - 2014. URL: https://www.u-ma.se/filter/Public/FREDHALL-ICE-FALLS (дата обращения: 11.10.2019). 
12. Наумов С.В., Ермоленко А.А. Категория места в современной теории экономического пространства // Пространственная экономика. - 2020. - Т. 16. - С. 101-123.

13. Социальное пространство современного города / под. ред. Г.Б. Кораблевой, А.В. Меренкова. - Екатеринбург: Изд-во Урал. ун-та, 2015. - 252 с.

14. Шулепов Е.Б., Задумкин К.А., Щербакова А.А. К вопросу использования проектного подхода в стратегическом управлении крупным городом // Проблемы развития территории. - 2020. - № 2 (106). С. 19-33.

15. Филиппов А.Ф. Пустое и наполненное: трансформация публичного места // Социологическое обозрение. - 2009. - Т. 8. - № 3. - С. 116-127.

16. Ан А.Л. Роль общественного пространства в муниципальных образованиях // Вопросы государственного и муниципального управления. - 2012. - № 1. - С. 174-184.

17. Mouratidis K. Built environment and social well-being: How does urban form affect social life and personal relationships? // Cities. - 2018. - V. 74. - P. 7-20.

18. Дормидонтова В.В., Ерёмина А.М. Принципы композиционной гармонизации современного городского ландшафта // Лесной вестник. - 2018. - Т. 22. - № 4. - С. 51-58.

19. Институт экономики города. URL: http://www.urbaneconomics.ru/sites/default/files/rmp_4_2018_1214 2.pdf (дата обращения 09.03.2021).

20. Глазычев В.Л. Политическая экономия города: учебное пособие. - М.: Издательство «Дело» АНХ, 2009. - 192 c.

21. Капков С.А. Трансформация городских общественных пространств (социально-философские аспекты): дис. ... канд. философ. наук. - Москва, 2020. - 198 с.

22. Благоустройство дворов: как подготовить и реализовать инициативный проект местного сообщества / И.В. Генцлер, Т.Б. Лыкова, Т.К. Байкова, Е.П. Железова. - Москва: Фонд «Институт экономики города», 2018. - $48 \mathrm{c}$.

23. Индекс качества городской среды - инструмент для оценки качества материальной городской среды и условий еe формирования. URL: https://xn----dtbcccdtsypabxk.xn--p1ai/\#/ (дата обращения 23.11.2020).

Поступила 15.03.2021 2. 
UDC 332.1

\title{
QUALITY OF THE URBAN ENVIRONMENT: ISSUES OF ORGANIZATION AND SOCIALIZATION OF PUBLIC SPACE
}

\author{
Olga V. Artemova, \\ artemova.ov@uiec.ru \\ Anastasia N. Savchenko, \\ savchenko.an@uiec.ru \\ Chelyabinsk Branch of the Institute of Economics, \\ Ural Branch of the Russian Academy of Sciences, \\ 68, Kommuny street, Chelyabinsk, 454091, Russia.
}

\begin{abstract}
Olga V. Artemova, Dr. Sc., branch director, Chelyabinsk Branch of the Institute of Economics, Ural Branch of the Russian Academy of Sciences.
\end{abstract}

Anastasia N. Savchenko, Cand. Sc., senior researcher, Chelyabinsk Branch of the Institute of Economics, Ural Branch of the Russian Academy of Sciences.

The paper considers the approaches to definition of the concept of «Public space» of the city and introduces the classification of the types of public spaces, including according to new features introduced by the authors (human life cycle, natural and climatic conditions of the territory). The authors have revealed the city public space influence on local community socialization; it is shown that its contentfulness is associated with the involvement and activity of citizens. The problems in the organization of public space are identified, an algorithm of actions for the participation of citizens in the transformation of the public space of the city is proposed. An assessment of the quality of the urban environment of the Ural and Siberian cities is given. The purpose of the study is to identify the effect of the public urban space, its condition and characteristics on urban community socialization. Methods: spatial approach to the analysis of the urban environment, grouping and classification of types of public spaces, case analysis of the practices of organizing public spaces, expert assessments. Results. The place and role of the city's public spaces in the development of the urban environment were clarified, signs of socialization of public spaces were determined, a matrix was proposed as a tool for organizing public urban spaces for city residents.

Key words: Public goods, urban environment, public space organization, public space socialization.

The article was prepared in accordance with the Research Plan of the Federal State Budgetary Scientific Institution «Institute of Economics of the Ural Branch of the Russian Academy of Sciences» for 2021.

\section{REFERENCES}

1. Ukaz o natsionalnykh tselyakh razvitiya Rossii do 2030 goda [Decree on the national development goals of Russia until 2030]. Available at: http://kremlin.ru/acts/news/63728 (accessed 9 March 2021).

2. Yashin S.N., Mosina L.A., Zakharova S.G., Shiryaeva Y.S. Upravlenie kachestvom zhizni naseleniya [Management of the quality of life of the population]. Ed. by S.G. Zakharova. Nizhniy Novgorod, Otkrytoe znanie Publ., 2019. 157 p.

3. Ageev I.A. Metodologicheskiy resurs istoricheskoy urbanistiki v sovremennykh issledovaniyakh gorodskikh prostranstv [Methodological resource of historical urban studies in modern researches of urban spaces]. Vestnik Tomskogo gosudarstvennogo universiteta, 2014, no. 385, pp. 79-84.

4. Votinov M.A. Osobennosti formirovaniya obshchestvennykh prostranstv v gorodskoy srede [Features of the formation of public spaces in the urban environment]. Vestnik BGTU im. V.G. Shuhova, 2014, no. 4, pp. 36-40. 
5. Gelfond A.L. Obshchestvennoe zdanie i obshchestvennoe prostranstvo. Dualizm otnosheniy [Public building and public space. Relationship dualism]. Academia. Arhitektura i stroitelstvo, 2015, no. 2, pp. 20-33.

6. Yakobson L.I. Gosudarstvenny sektor ekonomiki: ekonomicheskaya teoriya i politika [The public sector of the economy: economic theory and politics]. Moscow, SU HSE Publ., 2000. 367 p.

7. Batalina T.S. Analiz osobennostey formirovaniya obshchestvennogo prostranstva [Analysis of the peculiarities of the formation of public space]. Biznes i dizayn revyu, 2017, no. 1 (5), pp. 11.

8. Pachenkov O.V. Publichnoe prostranstvo goroda pered litsom vyzovov sovremennosti [Public space of the city in the face of modern challenges]. Novoe literaturnoe obozrenie, 2012, no. 117 (5/2012), pp. 67-83.

9. Salyahova M.R., Shulpina Yu.V. K voprosu ob aktualnosti formirovaniya vremennoy arkhitektury kak sposoba preobrazovaniya obshchestvennykh prostranstv $\mathrm{v}$ zimnee vremya [To the issue of the relevance of the formation of temporary architecture as a way of transforming public spaces in winter]. Izvestiya KazGASU, 2019, no. 4 (50), pp. 120-130.

10. Xing C.B., Zhang J.F. The preference for larger cities in China: Evidence from rural-urban migrants. China Economic Review, 2017, vol. 43, pp. 72-90.

11. Fredhall ice falls. The official website Bureau UMA, 2014. Available at: https://www.u-ma.se/filter/Public/FREDHALL-ICE-FALLS (accessed: 11 October 2019).

12. Naumov S.V., Ermolenko A.A. Kategoriya mesta v sovremennoy teorii ekonomicheskogo prostranstva [The category of place in the modern theory of economic space]. Prostranstvennaya ekonomika, 2020, vol. 16, pp. 101-123.

13. Sotsialnoe prostranstvo sovremennogo goroda [Social space of a modern city]. Eds. G.B. Korableva, A.V. Merenkova. Ekaterinburg, Ural University Publ., 2015. 252 p.

14. Shulepov E.B., Zadumkin K.A., Shcherbakova A.A. K voprosu ispolzovaniya proektnogo podkhoda v strategicheskom upravlenii krupnym gorodom [On the issue of using the design approach in the strategic management of a large city]. Problemy razvitiya territorii, 2020, no. 2 (106), pp. 19-33.

15. Filippov A.F. Pustoe i napolnennoe: transformatsiya publichnogo mesta [Empty and full: transformation of a public place]. Sotsiologicheskoe obozrenie, 2009, no. 3, pp. 116-127.

16. An A.L. Rol obshchestvennogo prostranstva v munitsipalnykh obrazovaniyakh [The role of public space in municipalities]. Voprosy gosudarstvennogo i munitsipalnogo upravleniya, 2012, no. 1, pp. 174-184.

17. Mouratidis K. Built environment and social well-being: how does urban form affect social life and personal relationships? Cities, 2018, vol. 74, pp. 7-20.

18. Dormidontova V.V., Eremina A.M. Printsipy kompozitsionnoy garmonizatsii sovremennogo gorodskogo landshafta [Principles of compositional harmonization of modern urban landscape]. Lesnoy vestnik, 2018, no. 4, pp. 51-58.

19. Institut ekonomiki goroda [The institute for urban economics]. Available at: http://www.urbaneconomics.ru/sites/default/files/rmp_4_2018_12-14_2.pdf (accessed 9 March 2021).

20. Glazychev V.L. Politicheskaya ekonomiya goroda [Political economy of the city]. Moscow, Delo Publ., 2009. 192 p.

21. Kapkov S.A. Transformatsiya gorodskikh obshchestvennykh prostranstv (sotsialno-filosofoskie aspekty). Dis. Kand. nauk [Transformation of urban public spaces (social and philosophical aspects). Cand. Diss.]. Moscow, 2020. 198 p.

22. Gentsler I.V., Lykova T.B., Baykova T.K., Zhelezova E.P. Blagoustroystvo dvorov: kak podgotovit $i$ realizovat initsiativny proekt mestnogo soobshchestva [Improvement of courtyards: how to prepare and implement an initiative project of the local community]. Moscow, Fond «Institut ekonomiki goroda» Publ., 2018. $48 \mathrm{p}$.

23. Indeks kachestva gorodskoy sredy - instrument dlya otsenki kachestva materialnoy gorodskoy sredy $i$ usloviy ee formirovaniya [The index of the quality of the urban environment is a tool for assessing the quality of the material urban environment and the conditions for its formation]. Available at: https://xn---dtbcccdtsypabxk.xn--p1ai/\#/ (accessed 23 November 2020).

Received: 15 March 2021. 